\title{
MEU CURSO E A HISTÓRIA: A INTERDISCIPLINARIDADE NO CURSO TÉCNICO INTEGRADO DO INSTITUTO FEDERAL DE EDUCAÇÃO, CIÊNCIA E TECNOLOGIA DO RIO GRANDE DO NORTE
}

\section{S. de OLIVEIRA E SILVA}

IFRN - Instituto Federal de Educação, Ciência e Tecnologia do Rio Grande do Norte - Campus Natal Central miriam.soares@ifrn.edu.br

\section{RESUMO}

O presente artigo retrata uma experiência realizada em sala de aula com a disciplina de História de quatro cursos técnicos da modalidade Técnico Integrado oferecido pelo Instituto Federal de Educação, Ciências e Tecnologia do Rio Grande do Norte, no ano de 2010. A experiência se consolidou com o projeto Meu Curso e a História, que possibilitou que os alunos do 3ㅇ ano, em seu 3으 bimestre, relacionassem conteúdos de História propostos naquele bimestre com assuntos do seu curso em específico. A proposta teve como objetivo desafiar os limites das disciplinas tanto de História como dos cursos em específico, num esforço interdisciplinar de reconstrução do conhecimento não só através da integração de conhecimentos produzidos em vários campos de estudo, como também numa associação, muitas vezes dialética, entre diferentes dimensões da realidade observada e estudada. A proposta teve como resultado a entrega de vinte e quatro trabalhos, num esforço de superação da fragmentação e da linearidade de produção do conhecimento.

PALAVRAS-CHAVE: interdisciplinar, história, disciplina, conteúdo.

\section{MY COURSE AND HISTORY: THE INTERDISCIPLINARITY IN THE INTEGRATED TECHNICAL COURSE OF THE FEDERAL INSTITUTION OF EDUCATION, SCIENCE AND TECHNOLOGY OF THE STATE OF RIO GRANDE DO NORTE}

\begin{abstract}
This paper reports an experiment accomplished in a class of History in four technical courses of the module 'Integrated Technical', which are offered by the Federal Institution of Education, Science and Technology of the State of Rio Grande do Norte, Brazil, in the year of 2010. The experiment has been consolidated with the project "My Course and History", which enabled the $3^{\text {rd }}$ year students, in their $3^{\text {rd }}$ quarter, to relate proposed History content of that quarter with subjects of their courses in specific. The proposal had as an objective to
\end{abstract}

challenge the limits of the disciplines in History as well as in their courses in specific, in an multidiscipline effort to rebuild knowledge not only through integration of knowledge produced in different study fields, but also in association, many times dialectical between different dimensions of the studied and observed reality. The proposal had as an outcome the delivery of twenty-four essays, in an effort to overcome the fragmentation and linearity of knowledge production.

KEY-WORDS: interdisciplinary, history, discipline, content. 


\section{MEU CURSO E A HISTÓRIA: A INTERDISCIPLINARIDADE NO CURSO TÉCNICO INTEGRADO DO INSTITUTO FEDERAL DE EDUCAÇÃO, CIÊNCIA E TECNOLOGIA DO RIO GRANDE DO NORTE}

\section{INTRODUÇÃO}

Os três níveis de ensino existentes no Brasil preparam os brasileiros para certas hierarquias profissionais presentes na sociedade. O modelo de escola normatizado pela legislação federal vigente oferece de um lado a educação propedêutica destinada a preparar educando para o acesso a níveis superiores de ensino, como também oferece uma formação de caráter técnico-profissional centrado no ideário da preparação para atender ao mercado de trabalho (FREITAG, 2005).

Os cursos oferecidos pelas escolas técnicas federais denominadas de Institutos Federais de Educação, Ciência e Tecnologia, criados pela Lei n. 11.892/2008 (BRASIL, 2008), possuem características diferentes dos cursos que normalmente proporcionam ao aluno apenas a formação básica do Ensino Médio. Esses cursos se apresentam em três modalidades diferentes, que são: os Cursos Técnicos Integrados, Cursos Técnicos Subsequentes e Cursos Técnicos Concomitantes.

Nos Cursos Integrados, os alunos frequentam aulas de disciplinas consideradas básicas como também das disciplinas de formação técnica. Nessa modalidade se faz necessária uma atenção especial para a interdisciplinaridade, visto que os alunos necessitam de elementos para conseguir fazer uma melhor relação dos seus estudos técnicos com as outras disciplinas consideradas básicas, que integram a grade curricular para melhor entenderem o mundo em que vivem.

É possível fazer uma ideia de quão difícil é para a prática pedagógica associar ambos os interesses tão bem dispostos em programas disciplinares dos cursos oferecidos nos Institutos Federais. No caso da disciplina de História, a sua trajetória foi marcada por fluxo e refluxo nas duas últimas décadas, passando ora por momentos em que foram identificadas algumas iniciativas para superar as práticas tradicionais de ensinar e aprender história como também passando por enfrentamento de dificuldades de operacionalização das propostas formuladas, buscando-se a superação dessas práticas tradicionais (PROGRAMA DE DISCIPLINA DE HISTÓRIA, 2010).

O presente artigo discorrerá sobre questões relevantes da Interdisciplinaridade num primeiro momento; em seguida apresentará um breve histórico da disciplina de História no IFRN, desde os anos de 1990 até a atualidade e concluirá na penúltima seção deste artigo com uma experiência realizada com a disciplina de História num trabalho denominado "O Meu Curso e a História", aplicado ao longo do 30 bimestre do ano de 2010, aos alunos de quatro cursos do Técnico Integrado, a partir dos assuntos trabalhados naquele bimestre na mencionada disciplina; e na última seção serão feitas as considerações finais.

\section{INTERDISCIPLINARIDADE}

A aprovação das Leis de Diretrizes e Bases - LDB, n. 9394, de 20 de dezembro de 1996, e a elaboração dos Parâmetros Curriculares Nacionais de 1998 sinalizaram para uma maior 
flexibilização dos conteúdos a serem desenvolvidos, possibilitando mudanças no currículo das escolas no sentido de reduzir a fragmentação característica de um currículo totalmente disciplinar e possibilitando uma redefinição quanto à forma como a seleção e organização de conteúdos e a definição de metodologias que vinham sendo efetuados nas escolas. A partir daí pesquisas comprovam que nos anos 1990 muitos trabalhos foram realizados abordando o tema da Interdisciplinaridade.

A tradição escolar se vale da fragmentação e da compartimentalização e incide sobre a maneira de interpretar o mundo. De acordo com essa tradição para se aprender o objeto é preciso dividi-lo em partes, o que em muitos casos resulta na impossibilidade de reconstrução das peças, ou seja, na dificuldade de remontagem do quebra-cabeça. Neste sentido, o todo se perde na atuação do detalhe, em relação ao particular. A perspectiva da fragmentação sempre foi alvo dos interesses dos grupos dominantes e sempre beneficiou o modo de produção capitalista, no sentindo de possibilitar a alienação do trabalhador e lhe ensejar num processo de repetição mecânica. A função social hegemônica da educação no sistema capitalista é preparar estudantes para se comportarem como futuros submissos aos patrões, assim como para enxergar na sociedade capitalista a última etapa histórica possível e os seus princípios como qualidades imutáveis da natureza humana (WELLEN H.; WELLEN H. 2010).

O modelo de escolarização não fugiu a essa orientação e resulta na divisão de disciplinas estanques que compreendem o currículo tradicional, enquanto a reconstrução da totalidade do conteúdo fica por conta do esforço pessoal do aluno que deverá por si só estabelecer as relações entre os diversos saberes oferecidos pelas disciplinas. É de se reconhecer que tal esforço não é uma tarefa fácil visto que não foi dada ao aluno a oportunidade de exercer o exercício da contextualização, nem de estabelecer relações de conteúdos diversos ao longo do seu crescimento intelectual. Para o aluno só lhe foi apresentado o conteúdo em partes e lhe foi ensinado a pensar de forma fragmentada, sem ter ao acesso ao conhecimento na sua complexidade (SILVA; PINTO, 2009).

De acordo com Paro (2010), para a grande maioria das pessoas educação é a passagem de conhecimentos e informações de quem sabe para quem não sabe e nesse processo, ressalta o autor, o que se destaca é o conteúdo a ser transmitido que ignora as características tanto do educador como do educando. Trata-se de uma visão tradicional da educação ainda muito presente na sociedade.

Com os avanços da tecnologia e a globalização a ciência e o mundo do trabalho sofrem um redesenho e exige da escola um novo perfil de sujeito do saber (SILVA; PINTO, 2009). Diante das novas exigências surge a necessidade de repensar a metodologia usada tradicionalmente na escola. Nessa perspectiva, a prática da interdisciplinaridade surge em oposição à especialização do conhecimento. Como afirma Morin (2011) "a técnica disciplinar parcela, desune e compartimenta os saberes, tornando cada vez mais difícil a sua contextualização".

É importante ressaltar que quando se busca trabalhar com a Interdisciplinaridade a matriz de todo o trabalho continua sendo disciplinar, ou seja, as diferentes disciplinas poderão dar a sua contribuição na compreensão de um fenômeno, situação ou problema, como também pode se observar a ação conjunta de diferentes áreas do conhecimento na elaboração e execução de projetos, pois dentro de cada disciplina há habilidades que precisam ser desenvolvidas e que perpassam outras disciplinas que podem ser trabalhadas de forma conjunta (LÜCK, 2009).

De acordo com o pensamento de Souza (2006), a Interdisciplinaridade Escolar no nível pedagógico pode ser entendida como um espaço de atualização em sala de aula da 
interdisciplinaridade didática, e por isso ela pode ser considerada uma categoria de ação, pois considera a dinâmica da sala de aula com todos os seus implicadores. Como afirma Paulo Freire (2011), o bom clima pedagógico-democrático é o que o educando vai aprendendo, à custa de sua prática mesma, que sua curiosidade, como sua liberdade, deve estar sujeita a limites, mas em permanente exercício.

Para Lück (2009) a Interdisciplinaridade não surgiu para desvalorizar as disciplinas e o conhecimento produzido por elas, ao contrário do que se pensa, a interdisciplinaridade na visão da citada autora pode ser considerada um processo de circularidade entre as disciplinas. Neste sentido, a interdisciplinaridade assume um compromisso de elaborar um contexto mais geral já que o conhecimento é um fenômeno multidimensional e inacabado, sendo impossível a sua abrangência total.

Visto dessa forma, o termo interdisciplinaridade pressupõe um trabalho coordenado e com objetivo comum partilhado por vários ramos do saber de forma integrada e convergente. Como afirma Lück (2009) viver essa ideia não é uma tarefa fácil, requer reflexão e determinação, constituindo-se muito mais em compreensão empática, a partir de relatos e experiências, descrições de reflexões e análises e sintetizações de fragmentos dispersos na literatura.

\section{A DISCIPLINA DE HISTÓRIA NO IFRN}

Quando a instituição estava organizada como Escola Técnica Federal do Rio Grande do Norte (ETFRN) e não possuía um projeto político pedagógico próprio, o ensino de História atendia as concepções das políticas educacionais do Estado ditatorial, por intermédio da Lei 5692/71 e seu currículo era resultado de um modelo pedagógico único para todo o Brasil. A partir de 1992, o ensino de História sofreu uma redefinição de seus conteúdos, quando ocorreu a proposta de abandonar a concepção positivista em detrimento de um programa estruturado a partir de uma visão mais política e econômica com o foco para a História do Brasil (PROGRAMA DE DISCIPLINA DE HISTÓRIA, 2010).

Como resultado dos debates nacionais em torno da reforma do ensino, é formulado o Projeto Político Pedagógico em 1995, que consagra um currículo que integra o ensino técnico com o Médio e divide o ensino integrado em áreas de conhecimento, a saber: Linguagens e Códigos e suas Tecnologias; Ciências da Natureza e suas Tecnologias; Ciências da Natureza, Matemática e suas Tecnologias; Ciências Humanas e suas Tecnologias. Nesse sentido, a disciplina de História foi adequada às novas orientações curriculares e foi elaborada uma proposta com a adoção de um novo viés metodológico definido a partir do eixo temático: "O Trabalho e a Indústria no Brasil", que possibilitaria fazer uma análise do processo histórico nacional brasileiro (PROGRAMA DE DISCIPLINA DE HISTÓRIA, 2010).

A publicação do decreto 2.208/97 que separou o Ensino Médio da Educação Profissional pôs fim à proposta adotada pela disciplina de História e depois da transformação em Centros Federais de Educação Tecnológica (CEFETs), manteve-se um caráter essencialmente propedêutico para o Ensino Médio, que se estruturou totalmente desvinculado do Ensino Técnico. Com o fim da 2.208/97, ocorreu uma nova reformulação do papel social da Rede de Educação Profissional que possibilitou o retorno do Ensino Médio Integrado ao Ensino Técnico. Neste sentido, no contexto de reconstrução do PPP de 2004, a disciplina de História é novamente reformulada, sem muito se diferenciar da proposta anterior, quando ainda é mantido o caráter da sequencialidade, mas possibilitando o professor à liberdade de explorar os temas como 
melhor lhe convier, o que dá margem para a formulação de projetos e metodologias distintas que de certa forma só enriquecem a prática do ensino de História na instituição (PROGRAMA DE HISTÓRIA, 2010).

\section{O PROJETO: MEU CURSO E A HISTÓRIA}

O projeto Meu Curso e a História surgiu a partir de uma proposta de relacionar os temas abordados no terceiro bimestre dos cursos do Terceiro Ano do Curso Técnico Integrado do IFRN Campus Natal Central, com assuntos das disciplinas técnicas de cada curso em específico. $O$ projeto apresentou o seguinte objetivo: Despertar o aluno para a pesquisa, a partir da busca pelo conhecimento de novas abordagens históricas como específicas do curso, abrindo caminho para a interdisciplinaridade e uma maior compreensão dos conteúdos propostos.

\section{METODOLOGIA}

A operacionalização ocorreu através da proposta do trabalho em grupo, com a apresentação dos temas que deveriam ser trabalhados a partir da relação com assuntos específicos da área técnica, baseando-se numa pesquisa do tema escolhido e fundamentando-se na relação dos conteúdos propostos. Neste caso, foram apresentados os seguintes temas relativos ao 3을 Bimestres do 3을 Ano dos Cursos Técnico Integrado:

- O Governo Geral no Brasil e os Jesuítas: A Centralização Política; A ação dos Jesuítas e as Missões.

- A Escravidão No Brasil: O Tráfico Negreiro; O Trabalho Escravo; As Formas de Resistência; O Quilombo de Palmares.

- A Economia e a Sociedade Colonial: Os Engenhos; A Produção de Açúcar; A Sociedade Patriarcal; Os Bandeirantes e a Economia Mineradora.

- O Iluminismo: As Principais Ideias e Representantes; O Liberalismo Econômico; A Enciclopédia; O Despotismo Esclarecido.

- Revolução Industrial: O Pioneirismo Inglês; O Cercamento dos Campos; Os Avanços Técnicos e a Industrialização; AS transformações das Sociedades na Era Industrial; A Questão Social.

Os assuntos propostos foram escolhidos e trabalhados por quatro turmas do 3 ㅇ Ano do Curso Técnico Integrado, sendo uma turma de Mecânica, composta por 33 alunos; uma turma de Turismo, com 24 alunos; uma turma de Geologia e Mineração, com 17 alunos e uma turma de Informática com 35 alunos.

O trabalho de pesquisa deveria ser apresentado de forma escrita contemplando os seguintes itens:

- Título

- Objetivo

- Justificativa da Escolha

- Corpo da Pesquisa 
- Conclusão

- Referências

A proposta inicial contava não só com a entrega das pesquisas como também com a apresentação oral dos grupos que deveriam fazer uma breve explanação sobre o objeto trabalhado, mas o próprio cronograma sofreu algumas modificações no andamento do 3으 bimestre de 2010, o que impossibilitou essa segunda modalidade, ficando então a proposta única de entrega da pesquisa para o final do bimestre.

\section{ANÁLISE DOS TRABALHOS}

\section{Turma de Mecânica}

A turma 3.202.1M é uma turma do curso de Mecânica matutino, cujo horário da disciplina de História no ano de 2010, correspondia as duas primeiras aulas da segunda-feira, ou seja, das 7 da manhã até as 08h30min. Com 33 alunos frequentando as aulas de História, a turma apresentou sete trabalhos dos quais três estavam relacionados ao tema da Revolução Industrial; dois estavam relacionados à Escravidão no Brasil; um relacionado ao lluminismo e outro relacionado à Economia e a Sociedade Colonial.

A fundamentação dada à relação do curso de Mecânica com A Revolução Industrial por um dos grupos foi de que a mecânica, sendo vista como a aplicação da matemática e física no projeto de construção, análise, manutenção e operação de sistemas mecânicos, foi observada a sua presença no Brasil Colônia, visto que instrumentos com baixa resistência, tenacidade, dureza e alta fragilidade foram utilizados na produção do maquinário, armas, utensílios domésticos e qualquer tipo de artefato, no sentido de melhorar e facilitar a vida naquele estágio de desenvolvimento. Neste sentido, a pesquisa aponta para o maquinário utilizado na produção de açúcar com destaque para os moinhos, que inicialmente foram utilizados por força motrizes animal e depois pela força hidráulica. A pesquisa teve a tecnologia como elo entre a disciplina de História e a Mecânica, com destaque para as engrenagens da mecânica do moinho hidráulico e do moinho mecânico, trazendo esclarecimentos sobre um aspecto que fica nas entrelinhas e por trás das ilustrações dos livros didáticos que suavemente mostram o pesado trabalho escravo no Brasil Colônia.

A pesquisa que trouxe à tona "O Maquinário da mão-de-obra escrava" visto dentro do tema A Economia e a Sociedade Colonial, abordou sobre as máquinas utilizadas nos engenhos para fazer o beneficiamento da cana-de-açúcar, fazendo uma minuciosa descrição de tal aporte mecânico e todo o processo de produção do açúcar e de seus derivados, fundamentando a pesquisa no princípio de funcionamento das máquinas que propiciavam a produção da cana-deaçúcar, que foi a base da economia colonial.

O trabalho que relacionou a mecânica com $O$ lluminismo buscou fundamentar no racionalismo, princípio iluminista, os valores que propiciaram o avanço da sociedade no sentido de buscar uma explicação para as coisas do mundo. Tal interesse culminou com o desenvolvimento da pesquisa e das leis da física que fundamentam os princípios da mecânica e de todo o aparato intelectual que possibilitou o advento industrial.

O trabalho que abordou o tema da Escravidão no Brasil relacionou o fim da escravidão com maior busca pelo maquinário no processo de substituição de mão-de-obra escrava pelo 
trabalho assalariado, sendo considerado, portanto um importante fator no processo de consolidação da prática capitalista no Brasil.

Todos os trabalhos apresentados procuraram através da pesquisa e de uma nova abordagem, evidenciar não só aspectos históricos como também conteúdos de seu curso específico que, relacionados um com o outro através do projeto interdisciplinar, conseguiram romper as fronteiras que engessam as disciplinas, minimizando a fragmentação que muitas vezes impossibilita uma visão holística e complexa do conhecimento proposto pelo ensino propedêutico.

\section{Turma de Geologia e Mineração.}

As aulas de História na turma de Geologia e Mineração concentravam-se nas segundasfeiras, no horário de $14 \mathrm{~h} 25 \mathrm{~min}$ às $16 \mathrm{~h} 10 \mathrm{~min}$. Atendendo à proposta do projeto do 30 bimestre, a turma respondeu com a apresentação de três trabalhos. O primeiro abordando em Economia e a Sociedade Colonial, a questão do esgotamento das minas, o que por sua vez relaciona aspectos do curso Geologia e Mineração com as questões históricas, a partir dos motivos físicos que golpearam a economia mineradora pondo fim a um ciclo econômico da História do Brasil. 0 segundo trabalho analisado, também enveredou pelo mesmo tema, indo ainda mais adiante, quando fez um estudo da sustentabilidade da mineração no período colonial e na atualidade, numa pesquisa que analisa também a questão da qualidade do trabalho empregado e o seu caráter exploratório.

O terceiro trabalho abordou o tema Iluminismo, cujas ideias possibilitaram a apresentação de uma teoria que explicava a formulação da terra, refutando a versão bíblica da criação em sete dias. Nesse período, segundo a pesquisa apresentada, grandes iluministas desenvolveram ideias relacionadas à geologia e mineralogia, como por exemplo Nicolaus Steno $(1638-1686)$ que é considerado por muitos o pai da Mineralogia. Steno fez um estudo sobre os fósseis em sua obra: Discurso Prévio a uma dissertação sobre um corpo sólido contido naturalmente num sólido, que provocou um grande choque nos conceitos admitidos naquela época, pois para as Sagradas Escrituras, a terra tinha permanecido inalterada desde a sua criação.

A pesquisa apresentou vários pensadores com suas contribuições para o avanço da ciência e renovação do conhecimento que possibilitou o surgimento da Geologia, cujo pensamento foi de encontro com aos proclamados pela Igreja Católica.

\section{Turma de Turismo}

As aulas de História da turma de Turismo no ano de 2010, ocorriam nos dois primeiros horários do vespertino, ou seja, de 13:00 às 14:20. A turma atendeu a proposta interdisciplinar com a apresentação de quatro trabalhos relacionando conteúdos do terceiro bimestre de História com aspectos específicos do seu curso. Neste caso foram apresentados dois trabalhos relacionados com a Revolução Industrial; um com o lluminismo; um com a Economia e a Sociedade Colonial e outro com a Escravidão no Brasil.

Um dos grupos que relacionou o conteúdo da Revolução Industrial com aspectos do curso de turismo buscou mostrar os benefícios da Revolução Industrial para o desenvolvimento do Turismo. Um dos fatores abordados na pesquisa foi a nova divisão do tempo, com a introdução do tempo inoperante, quando uma nova mentalidade começa a permear as sociedades industrializadas provocando grandes implicações nas vidas das pessoas, que passam a vislumbrar um novo horizonte de vida com a introdução de viagens turísticas como meio de entretenimento para superar o stress provocado pela intensidade da vida urbana. 
O desenvolvimento da atividade turística foi abordado não só pela via do tempo, como também através da minuciosa relação dos aspectos econômicos, visto que a Europa se beneficiava com as explorações imperialistas que convergiam para seu continente uma grande soma de capital, que possibilitou que a classe burguesa viajasse mais. Outro aspecto também abordado na pesquisa foi o desenvolvimento dos transportes, com a construção das estradas de ferro utilizadas para escoar as mercadorias industrializadas que movia o capital, também possibilitou que trilhassem pelas mesmas linhas férreas vagões com pessoas que buscavam novos recantos para suas horas de lazer e descanso, iniciando uma atividade turística naquele momento histórico, visto que os meios de comunicação se tornavam mais eficientes e emergiam como um efeito colateral do próprio processo de industrialização que ditava as suas necessidades e regras. O trabalho conclui lembrando que o turismo moderno só surgiu mesmo no século XX, mas que é fruto do desenvolvimento provocado pela Revolução Industrial que propiciou o surgimento da burguesia que com tempo e dinheiro buscou novos destinos para as suas viagens de descanso e lazer e iniciaram a atividade turística como ramo da economia e fator gerador de renda.

O segundo trabalho que relacionou o turismo com a Revolução Industrial explorou a questão socioeconômica do turismo no seu aspecto como geradora de renda e de serviços, visto que o turismo se tornou uma "indústria" que contribui com $11 \%$ do Produto Interno Bruto (PIB) mundial, e que gera cerca de 200 milhões de empregos no mundo. Outro aspecto importante na relação entre a Revolução Industrial e o desenvolvimento do Turismo feito pelo grupo foram os benefícios advindos das conquistas sociais dos trabalhadores que com as férias remuneradas e o décimo terceiro salário possibilitou o desenvolvimento da prática do turismo.

O terceiro trabalho analisado da turma de Turismo teve como tema "O lluminismo e suas relações com o turismo". Neste trabalho, os alunos buscaram mostrar a relação entre o Iluminismo e o Turismo através das mudanças provocadas pela mudança de pensamento que proporcionou o Grand Tour, conhecida como uma tradicional viagem pela Europa realizada principalmente por jovens da alta classe social. O costume floresceu desde os anos de $1.600 \mathrm{e}$ estava sempre associado a um determinado itinerário que foi cada vez mais sendo estimulado e facilitado pelos benefícios promovidos pelo desenvolvimento tecnológico. 0 valor primário do Grand Tour está relacionado ao fato de que era uma rara oportunidade de se conhecer e admirar certas obras de arte associada ao legado cultural da Antiguidade Clássica e do Renascimento. 0 Grand Tour teve mais do que uma importância cultural, representou o controle da classe dominante pela via cultural antes de sua expressão pelo poder econômico.

O trabalho que relacionou o turismo com A Economia e a Sociedade Colonial explorou o turismo nas cidades coloniais como Ouro Preto, Tiradentes e outras cidades de heranças coloniais que atualmente tem na atividade turística uma grande fonte de renda. A pesquisa destaca os monumentos históricos como as igrejas de Minas Gerais, em Ouro Preto, cujo interior é adornado por ouro e ressalta as obras barrocas de autoria de Antônio Francisco Lisboa, popularmente conhecido como Aleijadinho.

Outro aspecto destacado pelo grupo no trabalho sobre A Economia e a Sociedade Colonial e o Turismo foi em relação ao legado deixado pela cultura africana que exerceu o trabalho escravo no Brasil durante todo o período colonial.

Como escreveu o grupo:

A cultura brasileira, que tanto atrai turistas do mundo inteiro, tem como principal base a cultura, a culinária e costumes africanos. Podemos citar o samba e a feijoada. 
O turismo no Brasil se valoriza do legado cultural deixado pelos africanos que ajudaram com seu sangue e suor a construir uma identificação mais própria da nação brasileira, e que atualmente atrai turistas não só das diversas regiões do país, como também dos mais longínquos recantos do mundo para provar da culinária e admirar a dança e a música iniciadas timidamente pelos tambores e batuques nos terreiros dos engenhos.

A análise do quarto e último trabalho aponta para uma relação das implicações da escravidão exercida no Brasil colônia com a atividade turística, com destaque para as cidades de Salvador e Rio de janeiro, lugares onde ocorreu uma forte entrada e presença da mão-de-obra escrava e que são atualmente pólo de atração turística, onde se exibe muito das heranças culturais deixadas pelos descendentes africanos exibidos na culinária, na dança, na música e no artesanato. Neste sentido, podemos observar que grandes pólos turísticos de hoje no Brasil é alimentado pelo legado cultural deixado pela presença africana no processo de construção da sociedade.

\section{Turma de Informática}

A turma de Informática tinha no ano de 2010 o 3으 e 4은 horários do vespertino das terçasfeiras destinados as aulas de história, ou seja, de $14 \mathrm{~h} 25 \mathrm{~min}$ as $16 \mathrm{~h} 10 \mathrm{~min}$. A turma, composta por 35 alunos, respondeu à proposta com seis trabalhos relacionando conteúdos da Revolução Industrial com aspectos de Informática; Três trabalhos relacionados com 0 lluminismo e um trabalho com a Economia e a Sociedade Colonial.

Sobre análise dos trabalhos que relacionaram com a Revolução Industrial pode-se observar na pesquisa a busca pelos princípios da Informática na distante Revolução Industrial, quando se relembra alguns cientistas da época, com destaque para Charles Babbage.

Segundo a pesquisa do grupo:

O primeiro e principal objetivo de Babbage era criar uma máquina de calcular que evitasse os frequentes erros causados pelo modo manual. Seu segundo projeto era criar uma máquina analítica que pudesse somar, subtrair, multiplicar e dividir e efetuar operações em sequência e armazenar os resultados intermediários de até mil números de 50 dígitos, antecipando o futuro do computador.

Continuando a análise do trabalho, o grupo estreita ainda mais a relação entre a Revolução Industrial e a Informática, que mesmo estando distante por alguns séculos, pode-se afirmar que a Revolução Industrial, que promoveu o advento da máquina em substituição ao trabalho do homem, com a automação das tarefas foi de igual importância para o desenvolvimento da informática que também veio substituir funções humanas no mundo do trabalho.

O segundo trabalho analisado abordou a Revolução Industrial e a Evolução do Hardware, quando no século XVII vários pesquisadores investiram na criação e no aperfeiçoamento das máquinas. $O$ foco da criação da época foram as calculadoras para que fosse possível a resolução de cálculos em maiores proporções e em menos tempo. O aperfeiçoamento da calculadora foi importante para se chegar a várias descobertas que possibilitaram o aperfeiçoamento dessas máquinas. Nesse processo de evolução é possível observar o desenvolvimento da Máquina Analítica, que dispunha de programa, memória, unidade de controle e periféricos capazes de entrada e saída. Essa máquina era capaz de calcular automaticamente tabelas de logaritmos e funções trigonométricas. A máquina operava por uma manivela e pesava algumas centenas de 
quilos. A pesquisa destaca também uma figura feminina chamada Ada, que compreendeu o funcionamento da Máquina Analítica e escreveu os melhores relatos sobre o processo, além de criar programas para a máquina, tornando-se a primeira programadora de computador do mundo. Nesse processo de evolução das máquinas iniciado a partir da Revolução Industrial, a pesquisa identifica a origem do computador que através da engrenagem eletromecânico abria o caminho para a sua evolução até entrar na era digital que revolucionou o sistema operacional através dos circuitos integrados que deram origem ao microprocessador.

O terceiro trabalho que aborda a Revolução Industrial focou para os benefícios relacionados à comunicação provocados pelo evento industrial, como a redução das distâncias e o aumento da comunicação, devido a melhoria dos meios de transportes, como também das vias de comunicação com a ampliação das estradas de ferro, transporte a vapor que passaram a aproximar mais as pessoas e os lugares. Na atualidade, a informática exerce um papel semelhante, quando as novas tecnologias da informação têm ampliado e acelerado a comunicação, eliminando distancias e transpondo obstáculos num rápido fluxo de informações que dinamiza não só o mundo do trabalho como a sociedade num sistema de redes e de interação social num mundo globalizado.

O quarto trabalho se refere as transformações provocadas pela Primeira Revolução Industrial, com o advento da máquina a vapor e o conjunto de novos inventos que possibilitaram a consolidação da produção industrial e a Terceira Revolução Industrial que serviu de base para o desenvolvimento da alta tecnologia na produção, com o emprego da microeletrônica, da robótica, das telecomunicações e a biotecnologia. O desenvolvimento de tantas áreas relacionadas à informática determinou a popularização da mesma que através da melhoria do desempenho e da rapidez dos serviços possibilitou o barateamento dos serviços.

Assim como a Revolução Industrial, a Terceira Revolução Industrial também veio modificar o perfil de uma economia e sociedade. A Revolução no século XVIII possibilitou o barateamento nos custos da produção têxtil, cujo consumo até então era reservado para uma minoria privilegiada. A Terceira Revolução Industrial, que também intensificou as comunicações, barateou custos através de sua inserção em todos os ramos da indústria com o empenho de criar produtos de melhor qualidade e mais barato. Assim como a Revolução Industrial revolucionou o mundo moderno a Terceira Revolução Industrial revolucionou o mundo contemporâneo.

O último trabalho que relaciona aspectos da Informática com a Revolução Industrial toma como eixo condutor de sua relação o "trabalho", e analisa como era naquela época e na atualidade, considerada a era da Informática. De acordo com a análise do material apresentado, com o advento da industrialização, mecanismos são acionados para que ocorra a desvalorização da mão-de-obra e a consequente exploração dos trabalhadores que passam a ser desprovidos dos seus meios de produção e passam a vender a sua força de trabalho por salários irrisórios numa jornada de trabalho diária que muitas vezes ultrapassava as 16 horas. Neste sentido, a condição social do trabalhador é cada vez mais desvalorizada e a sociedade vive o embate dos antagonismos sociais que mobilizaram todo o século XVIII e XIX e possibilitaram o surgimento de teorias sociais, algumas na tentativa de minimizar os efeitos deturpadores provocados pela Revolução Industrial. A pesquisa apresentada observa que na atualidade, embora muitos empregos ainda exigem do trabalhador a repetição dos movimentos na execução do seu trabalho, a informática possibilitou a formação de um novo perfil do trabalhador diante da introdução da tecnologia da informação e da reestruturação das empresas que levam ao aumento da demanda por trabalhadores mais qualificados e bem preparados para executar a sua 
atividade e vivem num processo de capacitação para acompanhar a evolução das novas descobertas que mobilizam a era da informática.

Um dos trabalhos da turma de Informática que abordou o tema do lluminismo com assunto específico do curso, apresentou a importância do Século das Luzes, que se caracteriza pelo racionalismo e por novo conjunto de ideias. Nesse contexto de efervescência cultural o grupo destacou a figura de Pascal e Descartes, dois grandes expoentes do lluminismo. Ambos forneceram elementos que proporcionaram o avanço das ciências em diversos campos, como na matemática, astronomia, física e ótica. Pascal destacou-se por inventar a primeira máquina de somar mecânica em 1642 e contribuiu coma geometria infinitesimal (a precursora do cálculo). É considerado também um dos pais da teoria da matemática de probabilidade e estudou a ordem dos coeficientes binominais que agora levam o seu nome (Triângulo de Pascal).

O grupo ainda reforçou a pesquisa afirmando a presença de Blaise Pascal na área da filosofia, sendo dele a frase "O Coração tem razões que a própria razão desconhece" presente na sua obra Pensées (Pensamentos). A pesquisa ainda associou o início da história dos computadores com Blaise Pascal e seu invento da primeira máquina automática de calcular. A máquina era feita de rodas dentadas que simulavam o funcionamento do ábaco, que realizava apenas soma e subtração e o resultado era mostrado numa sequência de janelinhas. Inicialmente esta máquina foi chamada de Pascalina, mas posteriormente recebeu o nome de Máquina Aritmética de Pascal. Ainda segundo o estudo do grupo, esse invento foi o "ponta pé" inicial para o desenvolvimento da informática, que possibilitou os grandes avanços tecnológicos da sociedade atual.

Outro trabalho que também abordou o lluminismo reforçou a importância de Descartes e Pascal para a busca do conhecimento. Ambos os cientistas através de suas críticas, evoluíram em seus conceitos na busca pelo conhecimento. Pascal, que criticava as ideias de Descartes, conseguiu num século que privilegiava o racionalismo encontrar espaço para a reflexão filosófica numa via aritmética, o que possibilitou o desenvolvimento da primeira máquina de calcular. Neste trabalho, o grupo concluiu ressaltando a importância do lluminismo para o desenvolvimento das ideias que serviram de base para a construção da sociedade contemporânea.

O último trabalho da turma de Informática que abordou o tema do lluminismo teve como título "lluminismo e a Lógica", que também se afirmou (a Lógica) a partir do racionalismo apresentado por Descartes. Segundo a pesquisa, o lluminismo elege a razão como grande instrumento de reflexão capaz de empreender instituições mais justas e funcionais. No entanto, se o homem não tiver a sua liberdade assegurada, a razão acaba sendo distorcida por entraves como o da crença religiosa ou pela imposição de governos que oprimem o indivíduo. Assim, a racionalização dos hábitos era uma das grandes ideias defendidas pelos iluministas. Semelhante a várias ideias que perpetuam nesse contexto histórico, a Lógica tem como base a razão, pois a própria (lógica) é uma ciência do raciocínio, devido ao fato de sua ideia está ligada ao processo de raciocínio correto e incorreto, que depende da estrutura de argumentos envolvidos nele, que foi alcançado graças à afirmação do homem como sujeito e a valorização da razão. A lógica estuda as formas ou a estrutura do pensamento que podem mudar em diferentes épocas. 0 exemplo apresentado na pesquisa é o do Antigo Regime, surgido e estabelecido a partir das ideias que eram desenvolvidas para atender a necessidade do sistema absolutista monárquico, alimentado pelo mercantilismo e que tinha o seu poder reafirmado pela Igreja, cujo sistema manteve as suas verdades favorecendo a classe poderosa. Com o questionamento de métodos, adquiridos por meio da razão, tais verdades mantidas pelo Antigo Regime foram questionadas 
para se chegar a uma nova verdade e derrubar os conceitos pré-estabelecidos. $\mathrm{O}$ grupo conclui o trabalho ressaltando a importância do lluminismo para o desenvolvimento do pensamento moderno permeado pela lógica que forneceu bases na sociedade contemporânea para o seu desenvolvimento no campo da Informática, com a Lógica de Programação, que é usada inclusive para a criação de softwares.

Um único trabalho relacionou a Informática com a Economia e Sociedade Colonial. Na pesquisa, o grupo resgatou as características da sociedade e da economia colonial destacando as diferentes ações na empresa açucareira, com suas diferentes funções, e destacaram que o reconhecimento de todos os benefícios resultantes da empresa açucareira só recaía sobre o senhor de engenho que era quem liderava o processo. O grupo relacionou a empresa açucareira, tão distante no tempo, com as grandes empresas desenvolvedoras de softwares, cujo exemplo foi caracterizado pela figura de Bill Gates, que ganhou a fama de todo um projeto que possibilitou a evolução da informática. Para o grupo, mesmo em épocas diferentes e distantes, as empresas ainda resguardam características que as aproximam no meio organizacional, seja adornada por engenhocas ou equipadas por modernos computadores numa network.

\section{CONSIDERAÇÕES FINAIS}

O projeto Meu Curso e a História proporcionou não só aos alunos como também a professora da disciplina uma nova abordagem dos conteúdos propostos e permitiu que cada turma abrisse as portas do seu curso para que a História pudesse promover uma relação mais íntima com os conteúdos de outras disciplinas, que fragmentados pelas regras do sistema, muitas vezes não tem a oportunidade de se relacionarem mesmo sendo expostos e comentados nas mesmas salas e turmas, mas em horários distintos e por diferentes professores, e dessa forma correm o risco de se esvaziarem no empobrecimento dos limites impostos pelo sistema.

Através da pesquisa os alunos puderam sentir além da ruptura dos limites impostos pelas disciplinas, o prazer e a dinâmica que acompanham os agentes históricos ativos no processo de construção do conhecimento, a partir do momento que eles souberem conduzir uma pesquisa, elegeram um objeto e trabalharam com esse objeto chegando finalmente a uma conclusão.

Um dos resultados importantes dessa proposta para a disciplina de História que é ministrada para diferentes cursos das áreas técnicas são as diferentes abordagens e ênfases que podem ser agora inseridas nessas novas visões da história, feitas com as lentes de quem se relaciona com as diferentes peças do quebra cabeça, cujas peças começam a se encaixar nesse gigantesco e complexo tabuleiro do conhecimento.

Como afirma Morin (2011), a educação do futuro se defronta com um problema universal e de difícil solução, pois de um lado os saberes desunidos, divididos, compartimentados, e de outro lado, as realidades ou os problemas cada vez mais multidisciplinares, transversais, multidimensionais, transacionais, globais e planetários. Neste sentido, a interdisciplinaridade corresponde a essa necessidade de superar a visão fragmentada de produção do conhecimento, como também de possibilitar essa articulação entre os diferentes saberes num esforço de recomposição da unidade entre as múltiplas representações da realidade (Lück, 2011). 


\section{REFERÊNCIAS BIBLIOGRÁFICAS}

1. AUgUSTO, Thaís; CALDERA, Ana Maria. Dificuldades para Implantação de Práticas Interdisciplinares em Escolas Estaduais, apontados por professores da área de Ciências da Natureza in Ensino de Ciências - v.12; pp139 - 154, 2007.

2. FREITAG, Bárbara. Escola, Estado e Sociedade. 7ạ Ed. rev. São Paulo: Centauro, 2005.

3. LÜCK, Heloísa. Pedagogia Interdisciplinar: Fundamentos Teórico-Metodológicos. 16a Ed. Petrópolis, RJ: Vozes, 2009.

4. MORIN, Edgard. Os Sete Saberes Necessários à Educação do Futuro. 2a Ed, rev. São Paulo: Cortez; Brasília DF: UNESCO, 2011.

5. SANTOS, Marco; CUTOLO, Luís Roberto. A Interdisciplinaridade e o Trabalho em Equipe no Programa de Saúde da Família, in Arquivos Catarinenses de Medicina, V. 32, n. 4; p 65 a 74. PR, 2003.

6. SILVA, Luíza Helena; PINTO, Francisco. Interdisciplinaridade: As Práticas Possíveis in: Revista Querubim - Revista Eletrônica de Trabalhos Científicos - Letras, Ciências Humanas e Ciências Sociais, 2009.

7. http//ww.uff.br//feufffrevistaquerubim/imagens/arquivos/artigos/interdisciplinaridade_entr e_teorias_e_praticas.pdf. Acesso em 16/10/2011.

8. SOUZA, Mariana Aranha. O SESI-SP em suas entrelinhas: Uma Investigação Interdisciplinar no Centro Educacional SESI 033 - São Paulo: SESI, 033. Dissertação de Mestrado; PUC/SP: 2006.

9. PARO, Vítor. Educação Como Exercício do Poder: Crítica ao senso comum em educação. 2a Ed.São Paulo: Cortez, 2010.

10. PROGRAMA DE DISCIPLINA DE HISTÓRIA; Instituto Federal de Educação, Ciência e Tecnologia do Rio Grande do Norte; Departamento de Educação e Ciência - DIEC; 2010.

11. WELLEN, Henrique; WELLEN, Hérica. Gestão Organizacional Escolar: Uma Análise Crítica. Curitiba: Ibpex, 2010. (Série Processos Educacionais). 